\title{
Preparation and characterization of perfluorocarbon microbubbles using Shirasu Porous Glass (SPG) membranes
}

\author{
Romain Melich ${ }^{\mathrm{a}, \mathrm{b}}$, Jean-Pierre Valour ${ }^{\mathrm{a}}$, Sébastien Urbaniak ${ }^{\mathrm{a}}$, Frédéric Padilla ${ }^{\mathrm{b}, \mathrm{c}, \mathrm{d}}$, Catherine Charcosset $^{\mathrm{a}, *}$ \\ ${ }^{a}$ Univ Lyon, Université Claude Bernard Lyon 1, CNRS, LAGEP UMR 5007, 43 boulevard du 11 novembre 1918, F-69100, \\ VILLEURBANNE, France \\ ${ }^{b}$ LabTAU, INSERM, Centre Léon Bérard, Université Lyon 1, Univ-Lyon, F-69003, LYON, France \\ ${ }^{c}$ Department of Radiation Oncology, University of Virginia School of Medicine, Charlottesville, VA, USA \\ ${ }^{d}$ Focused Ultrasound Foundation, 1230 Cedars Court, Suite 206, Charlottesville, VA, USA
}

\begin{abstract}
Microbubbles are increasingly used in several fields, such as medical imaging for enhanced contrast ultrasound imaging. Theses microbubbles usually consist of a gas core stabilized by surfactants molecules. In this study, a technique using Shirasu Porous Glass (SPG) membranes was used to produce perfluorocarbon microbubbles. The microbubbles obtained were characterized by their size, size distribution, and stability. The effect of several parameters on the microbubble's size was investigated related to the process (transmembrane pressure, $\Delta \mathrm{P}$, bubble point pressure, $P_{B P}$, shear stress, $\tau_{w}$ ), membrane pore size, $D_{p}$, and formulation (gas, surfactants in the aqueous phase). The transmembrane pressure nor the shear stress $\left(\tau_{w}\right)$ had influence on the microbubble's size or size distribution for $\Delta \mathrm{P} / P_{B P}<1.5$. The decrease of the membrane pore size from $1.1,0.5$, to $0.2 \mu \mathrm{m}$ led to lower microbubble size $13.3,6.36$, and $4.42 \mu \mathrm{m}$, respectively, which was associated with higher size distribution $16 \%, 24 \%$ and $31 \%$, respectively due to the higher Laplace pressure exerted on smaller microbubbles leading to their destabilization. With the $1.1 \mu \mathrm{m}$ pore size membrane, perfluorocarbon microbubbles were obtained with a diameter of $13.3 \mu \mathrm{m}$ and coefficient of variation (CV) of $16 \%$ when stabilized by sodium dodecyl sulfate (SDS), $15.6 \mu \mathrm{m}$ with CV\% of $23 \%$ when stabilized by Tween20, and 16.5 $\mu \mathrm{m}$ with CV\% of $26 \%$ when stabilized by Polyoxyethylene (40) stearate (PEG40S). These low CV were indication of monodispersity. Perfluorocarbon microbubbles had a smaller size than air microbubbles due to the lower surface tension that decreased the retention force, keeping the microbubbles at the pore opening. The stability study showed that the perfluorocarbon gas greatly increased the lifetime of the microbubbles with a slight increase in size of 1.3 after $90 \mathrm{~s}$ compared to 2.2 for air microbubbles. Overall, the membrane technique proved to be an effective, controlled and reproducible method to produce perfluorocarbon microbubbles at a high rate $\sim 0.6-1.5 \times 10^{+10}$ microbubbles $/ \mathrm{min}$. The key factor that determines the microbubbles formation is the adsorption kinetics of the surfactant at the new gas-liquid interface at the pore opening.
\end{abstract}

Keywords: Microbubble, Shirasu Porous Glass membrane, Membrane emulsification, Perfluorocarbon gas

\footnotetext{
*Corresponding author. Address: Univ Lyon, Université Claude Bernard Lyon 1, CNRS, LAGEP UMR 5007,43 boulevard du 11 novembre 1918, F-69100, VILLEURBANNE, France. Tel.: +33472431834

Email address: catherine.charcosset@univ-lyon1.fr (Catherine Charcosset)
} 


\section{Introduction}

Microbubbles have many potential applications in chemical and food industries, process engineering, water treatment, pharmaceutical and medicine. Due to their small size (typically around some microns), microbubbles have a very large gas-liquid interface area per unit volume. Microbubbles can thus increase 5 the efficiency of gas-liquid contacting devices, such as bubble columns, chemical reactors and fermenters [1]. In chemical industries, many gas-liquid reactions are based on the dispersion of gas bubbles in a continuous liquid phase to improve both hydrodynamics and mass transfer [2. In the food industry, the density and texture of products such gel and cream-based foods can be improved by monodisperse gas microbubbles in these materials [1]. In wastewater treatments, microbubble aeration can enhance ozone and oxygen gasliquid mass transfer [3]. In biomedical applications, microbubbles of 1-10 $\mu \mathrm{m}$ in diameter (sized to flow safely through a patients smallest capillaries) are used as ultrasound contrast agent for imaging, and are also studied for drug, gene and metabolic gas delivery [4, 5, 6, 7]. For these applications, monodispersity can be essential to improve echographic image quality [8], and also to limit Ostwald ripening effect by reducing effective Laplace pressure difference between polydisperse microbubbles, leading to better microbubble stability.

To design these gas-liquid contacting devices, the control of the size and size distribution of microbubbles generated is very important. To improve the manufacturing process, gases with reduced solubility in water, such as fluorocarbons can be used [9, 10, 11. Perfluorocarbons gases reduce the osmotic pressure [12, allowing an increase in the microbubble stability [13, 14] and presenting a lower surface tension [15]. The shell composition is also a key determinant for microbubble's physical properties as well as their acoustic behavior and imaging time. The shell core serves to prevent gas escaping from the core and avoid microbubbles coalescence [16, 17]. While for biomedical applications, microbubbles are shelled with phospholipids or albumin [18, soluble surfactants are also advisable for the production of microbubbles with perfluorocarbon, as they are easy to implement due to a rapid adsorption at gas-liquid interface, such as mixture of sorbitan monostearate Span 60 and polyoxyethylene 40 stearate (PEG40S) in aqueous media to produce perfluorocarbon-filled microbubbles by sonication [19]. Other possible shell materials include proteins, and biocompatible polymers such as Pluronic F68 [20].

The main techniques used to generate microbubbles are mechanical agitation or sonication and microfluidic technologies [7, 21, 22, 23, 24. In mechanical agitation, the hydrophobic gas is dispersed within an aqueous surfactant solution by disruption of the interface via high-shear mixing. Mechanical agitation is highly efficient at generating microbubbles at a high production rate, however the size distribution is highly polydisperse which requires further fractionation, for example by centrifugation [14], decantation [25] or flotation under gravity [11]. These methods are not ideally adapted for physicochemical investigations [10]. Microfluidic technologies include flow-focusing [26, 27, 28, T-junctions [29, 30] and electrodynamic atomization [31. These techniques provide microbubbles with very low polydispersity by a precise control of their size, however, microbubbles are produced at a very low rate and microchannels tend to clog when preparing microbubbles smaller than $10 \mu \mathrm{m}$. The microfluidic methods are time-consuming [22], which requires new microfluidic 
strategies in order to improve the production yield.

A membrane technique is an alternative to generate monodisperse microbubbles. This method was first proposed by Kukizaki et al. [1, 32, 33, 34, 35]. With this technique, monodisperse microbubble are produced by pushing air through a Shirasu porous glass (SPG) membrane (Figure 1). Air microbubbles were formed at the pore outlets and detached from the membrane by the shear force exerted by the continuous phase containing surfactant(s) flowing along the surface. The size and size distribution of the microbubbles depended on several parameters related to the membrane pore size [34, surface wettability of the SPG membrane [1, symmetry/asymmetry [33, process parameters such as shear stress [32, 34, transmembrane pressure 34, and surfactants in the aqueous phase [35. SPG membranes have also been used for microbubble aeration in a biofilm reactor for wastewater treatment [3]. Other membranes were used such as ceramic tubular membranes (PALL, France) to generate air or nitrogen microbubbles in aqueous or organic phase (water or heptane) for gas-liquid reactors [2]. Other advantages of using the membrane technique are low energy consumption, simplicity of design, easy scale-up, and reproducibility [36].

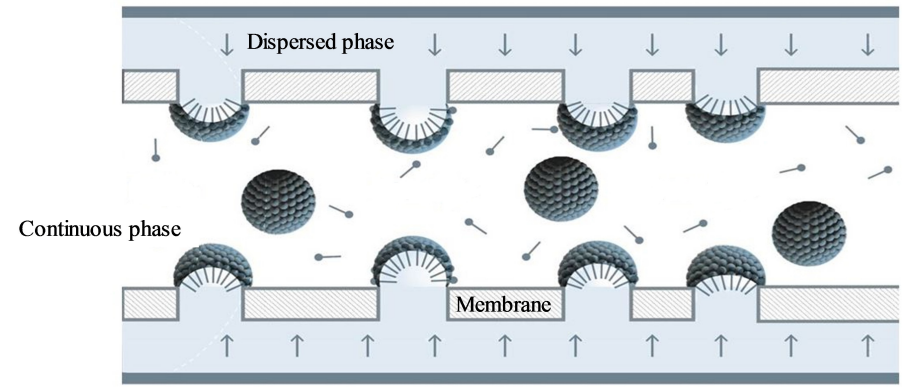

Figure 1: Schematic diagram of the membrane process principle where a gaseous phase is injected into the continuous phase composed of surfactants which stabilized the new interface

In this study, we considered the membrane technique to produce perfluorocarbon microbubbles. The microbubbles obtained with three different types of surfactants were characterized by their mean size and size distribution. The influence of the dispersed gaseous phase on microbubble formation was investigated. In addition, the microbubbles stability with each surfactant was observed. Surface tensions were also measured. The effect of several parameters on microbubbles characteristics were investigated such as shear stress, transmembrane pressure as well as surfactant types in the aqueous phase. In addition, perfluorocarbon microbubbles produced by the membrane technique versus sonication were compared.

\section{Materials and methods}

\subsection{Materials}

The gas-liquid dispersion system was composed of perfluorocarbon or air as the dispersed gaseous phase and a continuous aqueous phase. Octafluoropropane $\left(\mathrm{C}_{3} \mathrm{~F}_{8}\right)$ is a hydrophobic gas (vapor pressure of 792 
$\mathrm{kPa}$ and water solubility at $25{ }^{\circ} \mathrm{C}$ of $0.19 \mathrm{~mol} . \mathrm{m}^{-3}$ ) [37] purchased from F2 Chemicals Ltd (Preston, United Kingdom).

Three surfactants were used in this study: an anionic surfactant, sodium dodecyl sulfate (SDS), and two non-ionic surfactants, Polyoxyethylene (20) sorbitan monolaurate (Tween 20) and Polyoxyethylene (40) stearate (PEG40S) purchased from Sigma Aldrich (France). Ultrapure water was obtained using a Synergy unit system (Millipore, France) to prepare the aqueous solutions. The continuous phase was composed of $1.0 \mathrm{wt} \%$ surfactant in saline solution at $0.9 \%$ of $\mathrm{NaCl}$ for parenteral solution, since the microbubble preparation was found to be improved with the addition of $\mathrm{NaCl}$ [38. Microbubble diameter was found to decrease when surfactant concentration increased, to achieve a minimum diameter for a concentration above the critical micelle concentration (CMC). Surfactants were therefore used at concentration above CMC to achieve maximum effect 39 .

\section{2. $S P G$ membranes and membrane module}

Hydrophilic tubular SPG membranes were provided by SPG Technology Co. Ltd (Miyazaki, Japan). The SPG membranes had a length of $125 \mathrm{~mm}$ and an inner diameter of $8.3 \mathrm{~mm}$. These membranes are manufactured by a phase separation process of calcium aluminum borosilicate glass and subsequent acid leaching [32, 40, and have been widely used for production of emulsions and particles [41, 42. Membrane with a mean pore size of 1.1, 0.8 and $0.5 \mu \mathrm{m}$ were used. The mean pore size data was provided by the manufacturer.

The microstructure of the membranes was observed by scanning electron microscopy (SEM) using a FEI 80 Quanta 250 FEG microscope at the Centre Technologique des Microstructures at the University of Lyon (Villeurbanne, France). A fragment of SPG membrane was deposited on a flat steel holder. The sample was coated under vacuum by cathodic sputtering with copper. The samples were observed by SEM under an accelerating voltage of $10 \mathrm{kV}$. SPG membranes have cylindrical tortuous pores that form a three-dimensional network (figure 2). The membrane porosity is in the range of 0.53-0.60 [43]. SPG membranes are negatively charged and hydrophilic due to the presence of hydroxyl groups such as silanol groups on their surface. The dissociation of the silanol groups gives the negative charge of the SPG membrane surface 35 .

\subsection{Surface tension measurements}

The surface tension of surfactant solutions was measured by the pendant drop method using a Drop Shape Analysis tensiometer model DSA-10 Mk2 (Krüss). A rising bubble (volume approximately of $6 \mu \mathrm{l}$ ) of air or $90 \quad \mathrm{C}_{3} \mathrm{~F}_{8}$ was formed at the extremity of a needle using a syringe inside a quartz cell $(10 \mathrm{ml})$ containing $1.0 \mathrm{wt} \%$ of surfactant solution at room temperature. The formation time of the bubble was about $1 \mathrm{~s}$. The system was calibrated using the outer diameter of the needle (outer diameter of $1.507 \mathrm{~mm}$ ). The bubble was imaged with a CMOS camera, and its shape was then extracted by image analysis, and the surface tension, $\gamma$, was obtained as the best fit of the theoretical drop shape to the experimental profile [44]. 


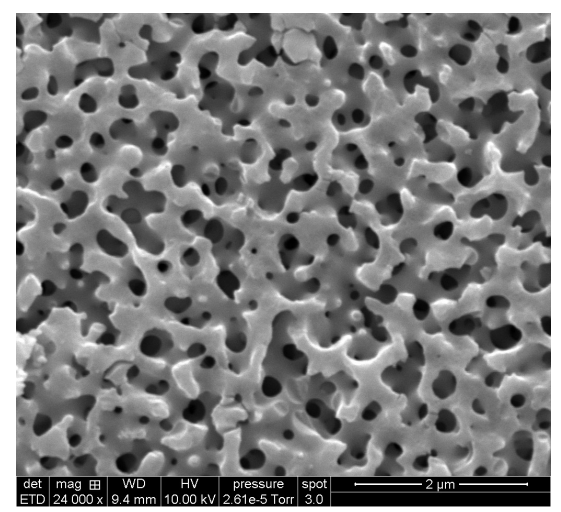

Figure 2: Scanning electron micrograph of the surface of the hydrophilic SPG membrane with a mean pore diameter of $0.2 \mu \mathrm{m}$ a pump (Quattroflow 150S, Pall, France). Two conditions of shear stress were tested, corresponding to a fluid pressure of $0.73 \mathrm{~Pa}$ (with no rod inside the membrane) and $34.8 \mathrm{~Pa}$ (when a rod was inserted inside 
the tubular membrane). The shear stress at the membrane wall, $\tau_{w}$, for a tubular membrane with a circular section was calculated using the equation:

$$
\tau_{w}=\frac{4 \mu V_{d}}{R}
$$

where $\mathrm{R}$ is the inner radius of the membrane tube $(\mathrm{m}), \mu$ is the dynamic viscosity (Pa.s) and $V_{d}$ is the mean velocity of the continuous phase in the tube $\left(\mathrm{m} \cdot \mathrm{s}^{-1}\right)$.

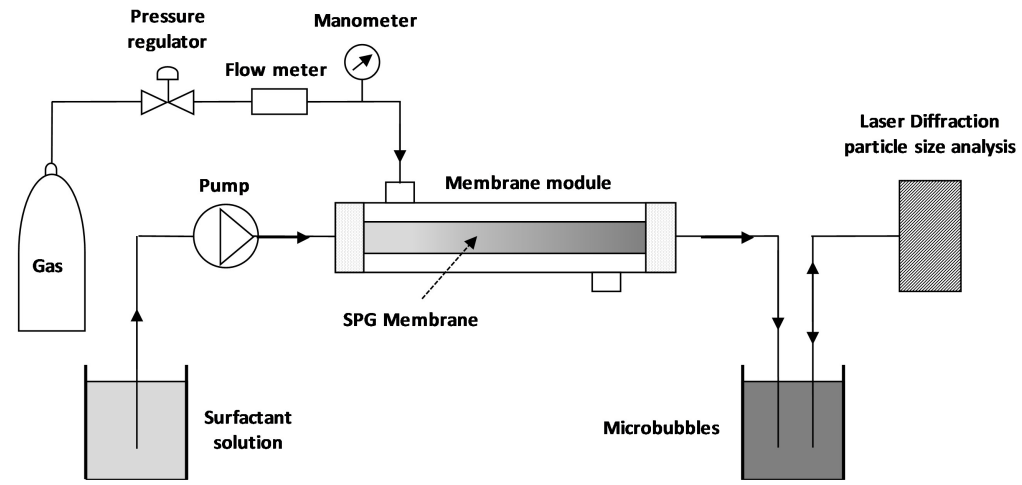

Figure 3: Experimental set-up to produce microbubbles using a tubular SPG membrane and to measure their size distribution by laser diffraction particle size analysis

To obtain a high shear stress, a PTFE (polytetrafluorethylene) rod with a diameter of $6.35 \mathrm{~mm}$ was introduced inside the tubular membrane. In this case, the shear stress at the membrane wall, $\tau_{w}$, was calculated using the following equation:

$$
\tau=4 \mu V_{d} \frac{R_{2}-R_{1}}{R_{1}^{2}+R_{2}^{2}-\frac{R_{2}^{2}-R_{1}^{2}}{\ln \left(R_{2} / R_{1}\right)}}
$$

where $R_{1}$ is the rod radius $(\mathrm{m})$ and $R_{2}$ is the inner membrane radius $(\mathrm{m})$ [45. Under these conditions, the mean velocity of the aqueous phase was $0.75 \mathrm{m.s} \mathrm{s}^{-1}$ (with no rod inside the membrane) and $5.18 \mathrm{m.s}{ }^{-1}$ when a rod was inserted inside the tubular membrane.

The gas was introduced on the external side and forced through the microporous membrane. At a pressure higher than the bubble point pressure, the gas that passed through the membrane generated microbubbles at the internal surface of the membrane. A pressure regulator (KPR1FRL412A20000, Swagelok), flowmeter (Model SLA5850S, Brooks instrument) and manometer (PGI-63B-BG2.5-LASX, Swagelok) were added to the set-up to control the gas pressure. The bubble point pressure was defined as the minimum transmembrane pressure, $\Delta \mathrm{P}$, needed to generate the first microbubbles appearing at the membrane surface. The bubble point pressure, $P_{B P}$, can be estimated from Young-Laplace equation:

$$
P_{B P}=\frac{4 \gamma \cos \theta}{D_{p}}
$$


where $\gamma$ is the equilibrium surface tension at the gas-liquid interface, $\theta$ is the contact angle, and $D_{p}$ is the mean pore diameter. From this equation, $P_{B P}$ can be estimated assuming that the contact angle is zero, due to the large number of hydroxyl groups on the membrane surface, which can be perfectly wetted by the aqueous phase [32. The theoretical and measured bubble point pressures for the SPG membranes as function of pore diameter are listed in Table 1. For all experiments, the transmembrane pressure applied was such that the ratio between transmembrane pressure and bubble point pressure, $\Delta \mathrm{P} / P_{B P}$, was in the range of 1.1-1.5. The dispersed gas phase flux, $\mathrm{J}$, was calculated from the volumic flowrate, $\mathrm{Q}$, measured using the flowmeter:

$$
J=\frac{Q}{A}
$$

where $\mathrm{A}$ is the effective membrane area $\left(27.4 \mathrm{~cm}^{2}\right)$.

\subsection{Characterization of microbubbles}

\subsubsection{Laser diffraction measurement}

The size and size distribution of microbubbles were measured using laser diffraction particle size analysis (Mastersizer 3000, Malvern Instrumentation, France) of a microbubbles sample diluted in a beaker of $500 \mathrm{ml}$ under agitation at $1500 \mathrm{rpm}$. The technique is based on the measurement of the intensity of light scattered as 150 a laser beam passes through a dispersed particulate sample. The Mie-scattering theory was used to convert light scattering data to microbubble size distribution. The refractive index was 1.0 for the gas phase [46] and 1.33 for the continuous phase. The microbubble size measurement was the average of three successive laser diffraction runs. The results were expressed by $D_{50}$, the median diameter.

Two parameters were used to characterize the width of the size distribution, first the span of the microbubble size distribution, expressed as:

$$
\operatorname{Span}=\frac{D_{90}-D_{10}}{D_{50}}
$$

where $D_{90}, D_{50}$ and $D_{10}$ are the diameters corresponding to 90,50 , and $10 \mathrm{nb} \%$ on the relative cumulative microbubble size distribution curve, respectively. Then, the polydispersity was characterized by $\mathrm{CV}$ (coefficient variation) which is a measure of the standard deviation to $D_{50}$ expressed in $\%$, using the equation 22, 29, 47, 48,

$$
C V=\frac{\sum n_{i}\left|D_{50}-D_{i}\right|}{D_{50} \sum n_{i}} \times 100
$$

where $D_{i}$, is the mean diameter of the class i and $n_{i}$ corresponds to the number of microbubbles of the class i.

To study stability, the microbubbles were collected at the membrane outlet and diluted into a beaker under agitation by a propeller to disperse homogeneously the MBs suspension. The microbubble suspension 
was the circulated in the measurement cell of the Mastersizer instrument during $90 \mathrm{~s}$ and the size measured

\subsubsection{Optical microscopy}

Immediate observation and recording are important for accurately measuring the size and size distribution of microbubbles. After producing microbubbles, an aliquot of the dispersion was immediately diluted and added to a Malassez counting chamber (Marienfeld-Superior). The observations were carried out with a microscope (Leica DM LM, France). A CCD video camera (Leica MC120 HD) was connected to the microscope to capture images, which were visualized with Leica Application Suite (LAS EZ) software (Version 3.4.0).

\section{Results and discussion}

\subsection{Comparison of sonication and membrane technique}

Microbubbles were prepared by sonication and the membrane technique using a membrane with pore size of $1.1 \mu \mathrm{m}, \Delta \mathrm{P} / P_{B P}=1.1$ and $1.0 \mathrm{wt} \%$ SDS. The bubble size distributions are shown in figure 4 The microbubbles obtained had a mean size and span of $D_{50}: 13.3 \mu \mathrm{m}$ and span: $0.527, D_{50}: 14.3 \mu \mathrm{m}$ and span: 1.11 using the membrane technique and sonication, respectively. The microbubble sizes were in the micrometric range size for both techniques, however, a narrower size distribution was obtained with the membrane than by sonication, which produced both smaller and larger bubbles. Figure 5 shows MBs

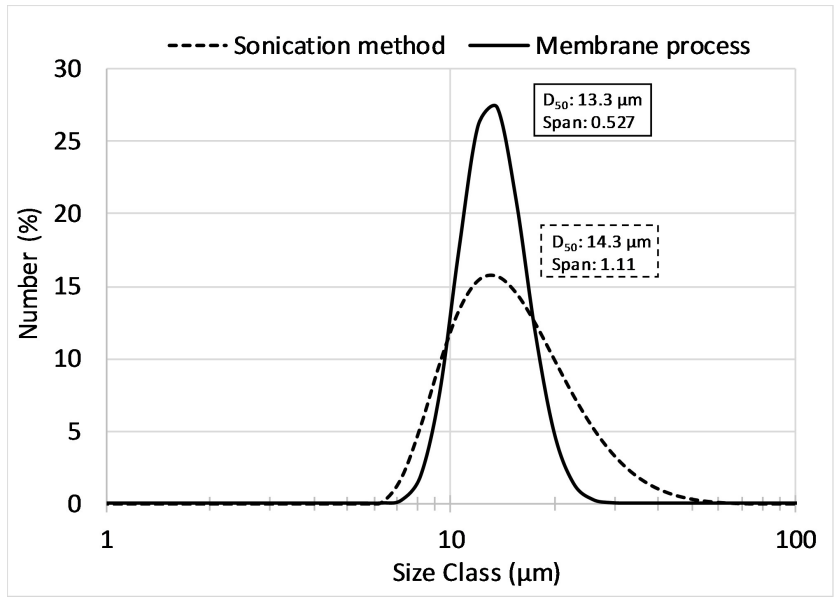

Figure 4: Comparison of the size of microbubbles generated by sonication and membrane with a mean pore diameter of $1.1 \mu \mathrm{m}$. For both experiments, the continuous phase used was $1.0 \mathrm{wt} \% \mathrm{SDS}$ in water and the dispersed phase was $C_{3} F_{8}$

Several techniques have also been compared by Stride [22] to produce microbubbles stabilized with L - $\alpha$ - phosphatidylcholine, Tween 80 and Polyethyleneglycol (PEG) 40 stearate: sonication, coaxial electrohydrodynamic atomisation (CEHDA) and T-junction microfluidic. The CV\% of microbubbles obtained were $150 \%$, $38 \%$, and $1 \%$, for sonication, CEHDA and microfluidic, respectively. The CV\% of microbubbles obtained 
185 by the membrane technique was around $17 \%$ and therefore was between the one obtained with CEHDA and microfluidic device as reported by Stride [22].

Indeed, the membrane technique can produce microbubbles with a span close to the span of the SPG membrane pore size distribution, in the range of 0.4-0.6. A similar observation was reported for the preparation of emulsions with droplet size of several microns by Vladisavljević et al. 49]. Monodispersed microbubbles can be produced with a membrane of narrow pore size distribution. However, the microbubbles size distribution depends on several other parameters, like the aqueous phase composition. Without surfactant, large polydisperse microbubbles were obtained due to microbubble coalescence at the pore opening by the membrane technique as shown by Kukizaki [35] or microchannel technique [48].

The yield of microbubbles obtained with the membrane was measured in the range $0.6-1.5 \times 10^{+10} \mathrm{MBs} / \mathrm{min}$ while the one reported by microfluidic techniques was around $2-6 \times 10^{+7} \mathrm{MBs} / \mathrm{min}$. Our results are in agreement with previous studies reporting yields obtained by sonication [21].

Sonication has to be performed carefully in particular by considering the probe size compared to the vessel size, the position of the probe into the liquid, the frequency, the intensity and the time of sonication 11. The membrane technique $\left(\sim 10^{+8} \mathrm{MBs} / \mathrm{s}\right)$ may give a better reproducibility between different operators due to fewer parameters involved. These differences between these two techniques are due to the mechanisms involved in microbubble formation. Sonication involves using high intensity ultrasound to produce a suspension of gas microbubbles in a liquid containing a suitable surfactant or polymer solution which adsorbs on the surfaces of the microbubbles to form a stabilizing coating. With the membrane technique, microbubbles are formed at the pore openings and can be detached by the continuous flowing aqueous phase. This technique involves much less energy, and the microbubbles size is controlled in part by the membrane pore size.

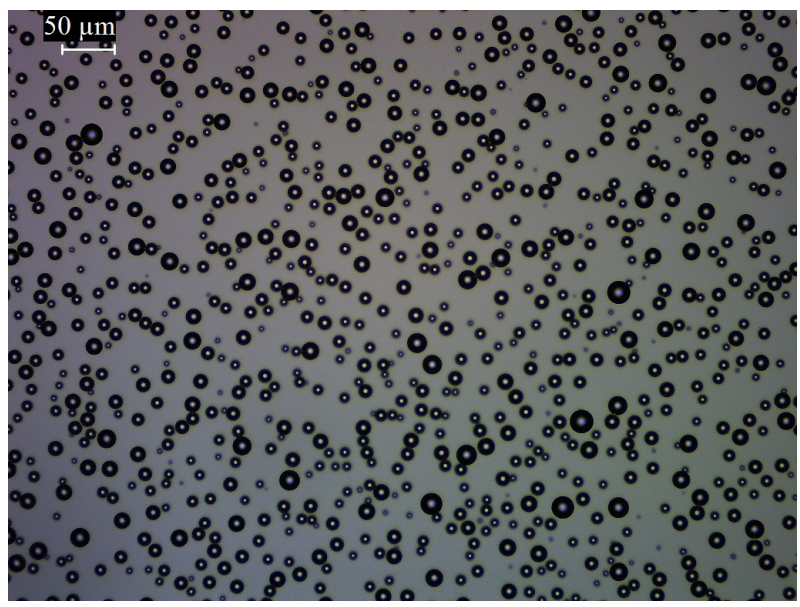

Figure 5: Immediate observation by optical microscopy of the size distribution of microbubbles generated by the membrane with a mean pore diameter of $1.1 \mu \mathrm{m}$. The continuous phase used was $1.0 \mathrm{wt} \%$ SDS in water and the dispersed phase was $C_{3} F_{8}$ 


\subsection{Influence of process parameters}

Microbubbles are formed in two steps, first microbubbles grow at the pore opening and then detach. The main forces that act on the microbubbles are the surface tension of the continuous phase, which is responsible for retaining the growing bubble at the pore opening, the static pressure difference force due to the pressure with a surface tension at $\mathrm{t}=0 \mathrm{~s}, \gamma_{0}$, equal to the surface tension at the equilibrium, $\gamma_{e q}$, (Table 1 ).

\begin{tabular}{|c|c|c|c|c|c|}
\hline Surfactants & Gas & $\gamma_{0}\left(m N . m^{-1}\right)$ & $\gamma_{e q}\left(m N . m^{-1}\right)$ & $P_{B P}($ Theo $)($ Bar $)$ & $P_{B P}($ Exp $)$ (Bar) \\
\hline \multirow{2}{*}{ SDS } & Air & 30.2 & 30.2 & 1.10 & 1.05 \\
\cline { 2 - 6 } & $C_{3} F_{8}$ & 29.5 & 29.5 & 1.07 & 0.98 \\
\hline \multirow{3}{*}{ Tween 20 } & Air & 42.0 & 37.5 & 1.36 & 1.35 \\
\cline { 2 - 6 } & $C_{3} F_{8}$ & 40.2 & 36.1 & 1.31 & 1.25 \\
\hline \multirow{3}{*}{ PEG40S } & Air & 49.4 & 47.3 & 1.72 & 1.55 \\
\cline { 2 - 6 } & $C_{3} F_{8}$ & 48.4 & 46.0 & 1.67 & 1.33 \\
\hline
\end{tabular}

Table 1: Measured values of surface tensions, $\gamma_{0}$, at $\mathrm{t}=0 \mathrm{~s}$, and at the equilibrium, $\gamma_{e q}$, between gas-liquid interface for surfactant solutions, and the calculated $P_{B P}($ Theo $)$ and the observed $P_{B P}(E x p)$ values of pression of bubble point with a mean pore size of $1.1 \mu \mathrm{m}$ (theo: Theoretical and Exp: Experimental)

\subsubsection{Influence of the transmembrane pressure}

For the three surfactants (SDS, Tween 20, and PEG40S) and the two gases (air and $C_{3} F_{8}$ ), $P_{B P}$ was calculated from the Young-Laplace equation (3) and the results are presented in Table 1. For all systems, the measured $P_{B P}$ values were close to the calculated values which assumed the contact angle between the membrane and the aqueous continuous phase was equal to zero. This indicates that the membranes used in this study were wetted correctly by the continuous aqueous solution. However, we noted a larger difference between theoretical and experimental $P_{B P}$ values for the two non-ionic surfactants (Tween 20 and PEG40S). 
An electrostatic repulsive interaction exists between the anionic polar groups of the SDS molecules and the membrane surface (negatively charged). While for non-ionic surfactants, although no strong repulsion exists between the hydrophilic groups of the molecules and the membrane surface, a surfactant layer covers the hydrophilic groups of the membrane. It could be explained by a hydrophilic interaction between the hydrophilic groups of the surfactant and the surface maintaining the surfactant at the membrane. This interaction may affect the hydrophilicity of the membrane surface and thus the contact angle formed between the membrane surface and the water phase. This results in a higher contact angle value, and therefore to higher theoretical $P_{B P}$ values than experimental ones. Experimental values were slightly lower than theoretical values, probably due the presence of larger pores than the mean pore size of $1.1 \mu \mathrm{m}$ which was used in the calculations. Indeed, a lower transmembrane pressure is needed to produce microbubbles through larger pores which is present due to the span pore size distribution around 0.4-0.6.

We studied the influence of transmembrane pressure on the perfluorocarbon microbubbles formation. For a concentration of $1.0 \mathrm{wt} \%$ SDS and with the $1.1 \mu \mathrm{m}$ pore size membrane, the variations of microbubbles size, size distribution and dispersed phase flux versus the ratio of $\Delta \mathrm{P} / P_{B P}$ are shown in Figure 6. At $\Delta \mathrm{P} / P_{B P}$ $<1$, no microbubbles were observed. Perfluorocarbon monodispersed microbubbles were generated with the SPG membrane at transmembrane/bubble-point pressure ratio in the range of $1<\Delta \mathrm{P} / P_{B P}<1.5$.

For a transmembrane/bubble point pressure ratio of $\Delta \mathrm{P} / P_{B P}<1.5$, the gaseous phase flux increased linearly with the ratio $\Delta \mathrm{P} / P_{B P}$, while both mean microbubble size and size distribution were nearly constant (figure 6). This observed increase in gaseous phase influx is in agreement with Darcys law, which suggests that the dispersed phase flux increases proportionally to the transmembrane pressure. Microbubbles grow until they reach a certain size and then detach at the pore opening. At these low pressures, the surface tension force dominates other forces and the microbubble size and size distribution are independent of the transmembrane pressure.

For $\Delta \mathrm{P} / P_{B P}>1.5$, the flux, microbubbles size and size distribution increased sharply, indicating the formation of larger microbubbles with a broad size distribution. This result can be explained by the static pressure difference force which dominates at these higher pressures.

The range of pressure for which no effect on droplet characteristics was observed was called the "sizestable zone" [51]. The size-stable zone was already observed by Kukizaki et Goto 34 for air bubbles, for a ratio $\Delta \mathrm{P} / P_{B P}<2$. For the same surfactant used in our experiments, SDS, Kukizaki et Goto 34 found that the size-stable zone existed at higher pressure. This can be explained by the comparison of the difference in surface tension at the equilibrium. Indeed, the surface tension was $36.5 \mathrm{mN} \cdot \mathrm{m}^{-1}$ in Kukizaki et Goto's article [34, while in our study, the surface tension was $29.5 \mathrm{mN} . \mathrm{m}^{-1}$ which implies a lower surface tension force for keeping the microbubble at the pore opening and a thus a faster microbubble detachment. This result was also reported by Kukizaki et al. [51] for droplets formed with two different concentrations of SDS, for which the lower interfacial tension presented a size-stable zone which ends at lower pressure.

The dispersed phase flux was $1.28-2.55 \times 10^{-5} \mathrm{~m}^{3} \mathrm{~m}^{-2} \mathrm{~s}^{-1}$ at $\Delta \mathrm{P} / P_{B P}<1.5$ and for the $1.1 \mu \mathrm{m}$ for 


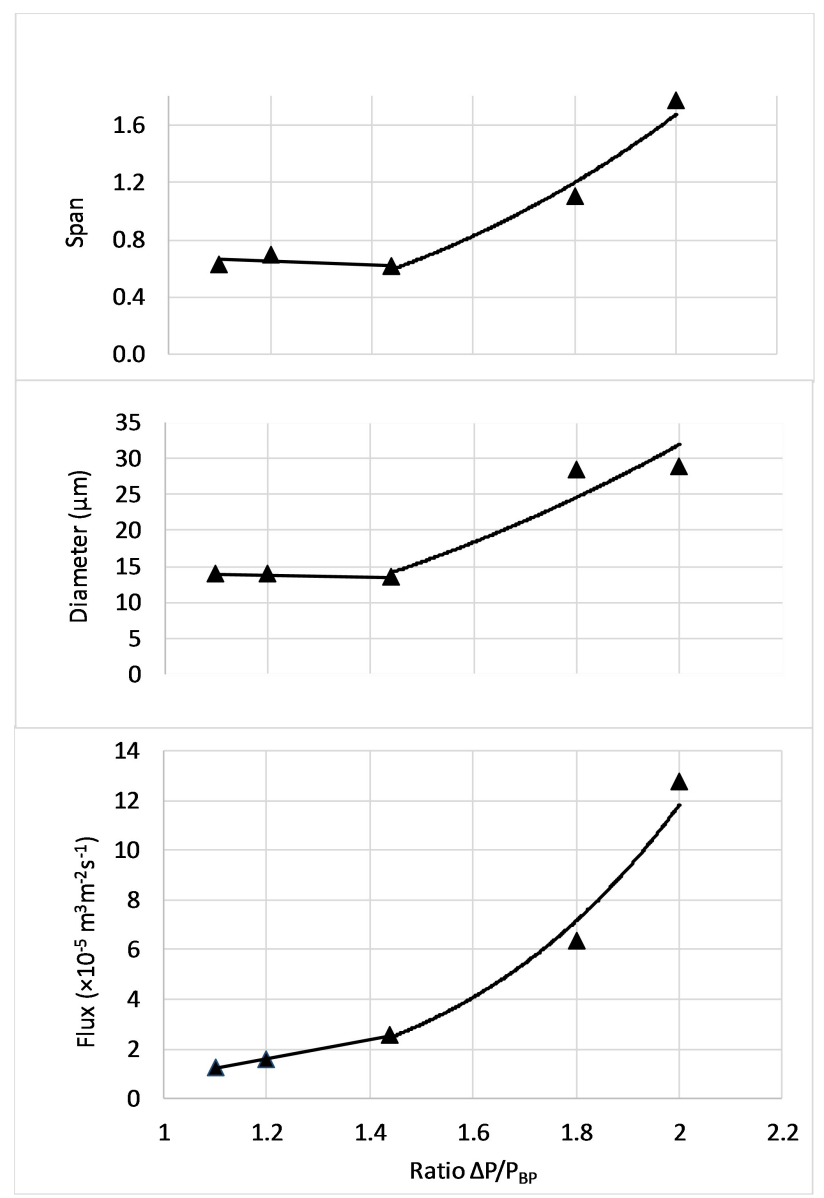

Figure 6: Influence of transmembrane/bubble point pressure ratio, $\Delta \mathrm{P} / P_{B P}$, on the gaseous phase flux, $J$, microbubble diameter, $D_{50}$, and span of the distribution. Experimental conditions: gaseous phase was $C_{3} F_{8}$, mean pore of $1.1 \mu \mathrm{m}$, with $1.0 \mathrm{wt} \%$ of SDS and a low shear stress

pore size membrane. These values are in agreement with the results of Kukizaki 33 who found $6-15 \times 10^{-5}$ $m^{3} m^{-2} s^{-1}$ for a symmetric SPG membrane with a size pore of $1.58 \mu \mathrm{m}$. The authors also showed that the use of asymmetric SPG membranes significantly increased the air flux (around 40 times) when compared to symmetric SPG membranes. The use of asymmetric SPG membranes could be also an alternative to increase the production rate of perfluorocarbon microbubbles.

The $\Delta \mathrm{P} / P_{B P}=1.1$ seems to be the best ratio to control the microbubble formation. Indeed, a ratio of 1 would be not necessary to activate a sufficient number of pores to obtain a great yield of microbubbles and a ratio around 1.4 or 1.5 produced a much higher gaseous flux which could lead to the loss of control of the microbubble formation.

\subsubsection{Influence of the wall shear stress}

The influence of shear stress of the continuous phase on microbubbles size and size distribution was measured for membranes with a mean pore size of $1.1 \mu \mathrm{m}$ and $\Delta \mathrm{P} / P_{B P}: 1.1$ (Figure 7). Perfluorocarbon 
microbubbles were prepared at two different shear stresses: $0.73 \mathrm{~Pa}$ (low shear stress) with a classical tubular module and 34.8 $\mathrm{Pa}$ (high shear stress) with an annular device. The low shear stress was used to recover the microbubbles at the membrane surface. With the $1.1 \mu \mathrm{m}$ pore size membrane, when increasing the wall shear stress from 0.73 to $34.8 \mathrm{~Pa}$, the microbubble size distribution was the same at $13.3 \mu \mathrm{m}$ and $13.1 \mu \mathrm{m}$, respectively. For both conditions, monodispersed microbubbles were produced with a CV\% of $16 \%$ at low shear stress and $17 \%$ at high shear stress. However, we observed a better size repeatability at a high shear stress as shown by the error bars in Figure 7

The influence of shear stress depends on other parameters like transmembrane pressure and interfacial tension. Vladisavljević [41] reported that two mechanisms of drop formation are possible: (1) a shearcontrolled detachment as a result of shear stress on the membrane surface and (2) a spontaneous detachment driven by interfacial tension. For example, Kukizaki 33, 34, observed that when increasing the shear stress, the bubble size decreased to a limit value beyond which the size was independent of the applied shear stress. Generally, variation in size occurred at very low stress values and at high transmembrane pressures. When preparing emulsions, Vladisavljević et Schubert [43] showed that at high transmembrane pressures, the droplet size decreased when increasing the wall shear stress from 0.6 to $47 \mathrm{~Pa}$, while at smaller transmembrane pressures, the size decreased very slightly, from 3.5 to $3.4 \mu \mathrm{m}$, for wall shear stress of $0.55 \mathrm{~Pa}$ and $91 \mathrm{~Pa}$, respectively.

In our study, the main principle to MBs formation at the tortuous and non-circular pores openings are driven by the second mechanism where the surface tension force dominates other forces (shear stress force, transmembrane pressure). In our case, the MBs size is independent on shear stress as we fixed a low transmembrane flux $\left(\Delta \mathrm{P} / P_{B P}: 1.1\right)$. The effect of the wall shear stress depends on the surface tension value. For example, Lepercq-Bost et al. [52] showed that at lower interfacial tension, the shear stress had a lower effect on the droplet diameter of emulsions generated by ceramic membranes. Indeed, at a lower surface tension, the force retaining the MBs or droplets at the pore opening is lower and the microbubble detachment is easier; this could explain the lower effect of shear stress on the droplet formation. In addition, our results show the same trend at a lower surface tension (1.0 wt\% SDS ; $\left.\gamma: 29.5 \mathrm{mN} . \mathrm{m}^{-1}\right)$ compared with the higher surface tension used by Kukizaki et Goto [34] (0.3 wt\% SDS ; $\gamma: 36.5 \mathrm{mN} . \mathrm{m}^{-1}$ ) who reported that the size was dependent on the shear stress. Indeed, the surfactant concentration influences considerably the surfactant adsorption kinetics and thus the dynamic surface tension [50]. At the higher surfactant concentration used in our study, the surface tension force dominated and the drag force created by the shear stress could not modify the microbubble size.

The mechanisms of microbubble production at low shear stress $(0.73 \mathrm{~Pa})$ may be compared to the ones suggested for spontaneous detachment of air MBs [32. This detachment is governed by the surface tension at a low dispersed phase flux as explained above. The adsorption kinetics of surfactant from bulk to the new gas-liquid interface is a key parameter in the spontaneous detachment due to the absence of continuous phase flux. In this case, the tortuous pores and irregular cross-section of the SPG membrane (Figure 2 facilitates 
the generation of the microbubbles. In addition, the dispersed phase deformation by the non-circular pores leads to the formation of a neck which may facilitate the MBs detachment, as observed for droplet production

315 53 .

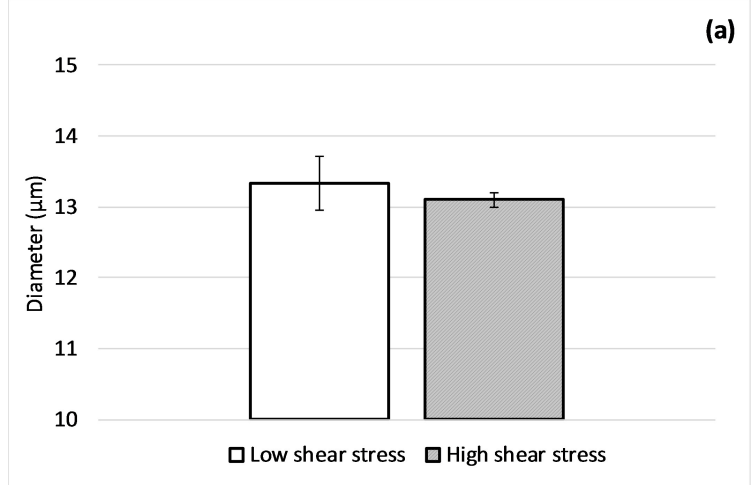

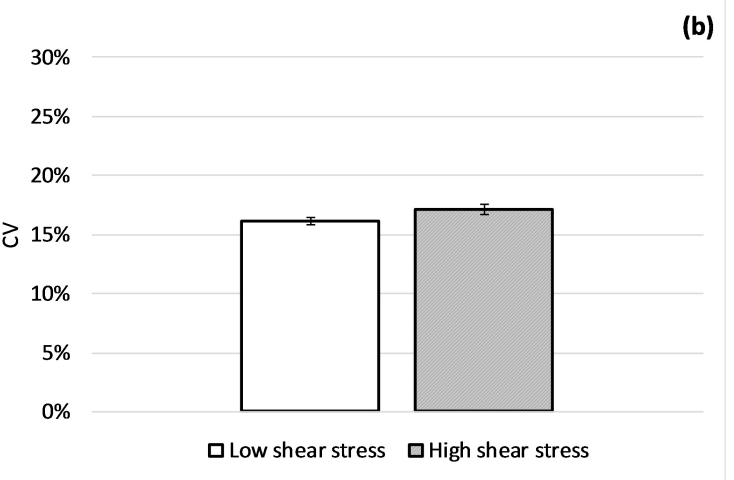

Figure 7: Influence of shear stress, $\tau_{w}$, (a) on the microbubble diameter and (b) on the CV\% for membrane mean pore size 1.1 $\mu \mathrm{m}$ at experimental conditions: continuous phase $1.0 \mathrm{wt} \% \mathrm{SDS}$ in water, gaseous phase $C_{3} F_{8}$, and ratio $\Delta \mathrm{P} / P_{B P}: 1.1$

\subsubsection{Influence of the pore size}

Perfluorocarbon microbubbles were prepared with the $0.2,0.5$ and $1.1 \mu \mathrm{m}$ pore size membranes. The three experiments were realized with a continuous phase containing $1.0 \mathrm{wt} \% \mathrm{SDS}, \Delta \mathrm{P} / P_{B P}: 1.1$ and at a low shear stress $(0.73 \mathrm{~Pa})$. The mean diameter of the microbubbles obtained is shown in Figure 8 , As expected, the microbubble mean size decreased when the membrane pore size was decreased. We observed a relationship between MBs size and pore size that seems exponential, but this would have to be confirmed with other pore size membranes. Other studies have reported linear relations with pore sizes in the range of 1 to $10 \mu \mathrm{m}$, where the $D_{M B s} / D_{\text {Pore }}$ ratio was between 7 and 10 depending of the surfactant used [33, 35]. In our study, we found a ratio of $D_{M B s} / D_{\text {Pore }}$ around 12 for the 0.5 and $1.1 \mu \mathrm{m}$ pore size membranes, in agreement with a possible linear relationship. But for the smallest pore size used of $0.2 \mu \mathrm{m}$, we found a ratio of 22. This result may be explained by an initial growth period due to the influx of air dissolved $\left(N_{2}\right.$ and $\mathrm{O}_{2}$ ) in water diffusing into the PFC MB [54. Also the growth caused a decrease of the Laplace pressure, which is inversely proportional to the MBs radius. The Laplace pressure, $\delta P$, is the main mechanism which is responsible of the disappearance of a $\mathrm{MB}$, given by the equation:

$$
\delta P=\frac{2 \gamma}{r}
$$

where $\gamma$ is the surface tension and $\mathrm{r}$ is the radius of the microbubble. The Laplace pressure is very high for microbubbles with small size. As a result, the microbubble size distribution changes over time, with the larger bubbles growing in size and the smaller microbubbles shrinking and then finally disappearing. This explains the polydisperse distribution, characterized by a coefficient of variation of $31 \%$, of microbubbles obtained with the $0.2 \mu \mathrm{m}$ pore size. 

found lower, in the range of 3.1-3.7 [43. Indeed, the oil droplet diameter decreased when increasing the dispersed phase viscosity [51. Therefore, for the same membrane, the oil droplets size is expected to be lower than the microbubbles size. This results in a $D_{\text {Droplets }} / D_{\text {Pore }}$ ratio lower than the $D_{M B s} / D_{\text {Pore }}$ ratio.

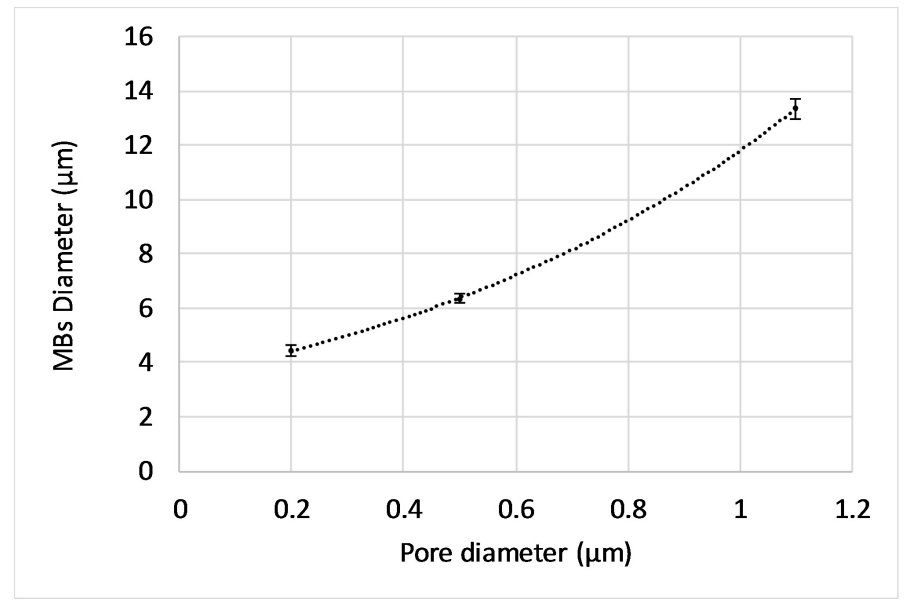

Figure 8: Influence of mean pore size $(0.2,0.5$ and $1.1 \mu \mathrm{m})$ on the microbubble diameter, $D_{50}$, at experimental conditions: continuous phase $1.0 \mathrm{wt} \% \mathrm{SDS}$ in water and ratio $\Delta \mathrm{P} / P_{B P}: 1.1$

\subsection{Influence of the surfactant type}

Perfluorocarbon microbubbles were prepared with different surfactants: SDS, Tween 20, PEG40S in the continuous phase at $1.0 \mathrm{wt} \%$. The $1.1 \mu \mathrm{m}$ pore size membrane was used, at a low shear stress $(0.75$ $m . s^{-1}$ ), and $\Delta \mathrm{P} / P_{B P}: 1.1$. Uniform size distributions were obtained with the various surfactants as shown in Figure 9. The smallest size and narrower dispersity were obtained with SDS, followed by Tween 20 and PEG40S. These results can be related to the equilibrium and dynamic surface tension of the various solutions measured by the pendant drop method (Figure 10). The three surfactants showed different equilibrium surface tension, the lowest being obtained with SDS $\left(29.5 \mathrm{mN} . \mathrm{m}^{-1}\right)$, then Tween $20\left(36.1 \mathrm{mN} . \mathrm{m}^{-1}\right)$, and the highest with PEG40S (46.0 $\left.\mathrm{mN} . \mathrm{m}^{-1}\right)$. As explained previously, at a lower surface tension, the force retaining the microbubble at the pore opening is lower and the microbubble detachment is easier, resulting in microbubbles with smaller size and better monodispersity with SDS.

In addition, the three surfactants showed different adsorption kinetics, the fastest adsorption kinetics being obtained with SDS and the lowest with PEG40S. When a microbubble is formed, the equilibrium surface tension, $\gamma_{e q}$, of the surfactant solution is not reached instantaneously. The surfactant molecules must diffuse at the new interface from the bulk solution, their hydrophobic tails directed toward the gaseous phase. For a surfactant with a fast adsorption kinetic, such as SDS, the surface tension at $\mathrm{t}=0 \mathrm{~s}$ is close to the equilibrium surface tension and the microbubbles detach faster from the membrane surface. This results in microbubbles with smaller size and better uniformity. Therefore, larger and more polydisperse microbubbles 
were obtained with surfactants having the slowest kinetics (Tween 20 and PEG40S). This result was also observed for oil droplets produced by membrane emulsification, as reported by Schröder et al. [50]: the faster a surfactant adsorbs at the new interface, the smaller the droplets produced. In addition, surfactants

SDS molecules and the membrane surface facilitates the microbubbles detachment by electrostatic repulsion and improves the size distribution compared to Tween 20 and PEG40S which do not present negative charges on their head groups. Overall, surfactants play an important role to produce monodisperse microbubbles by the membrane technique.

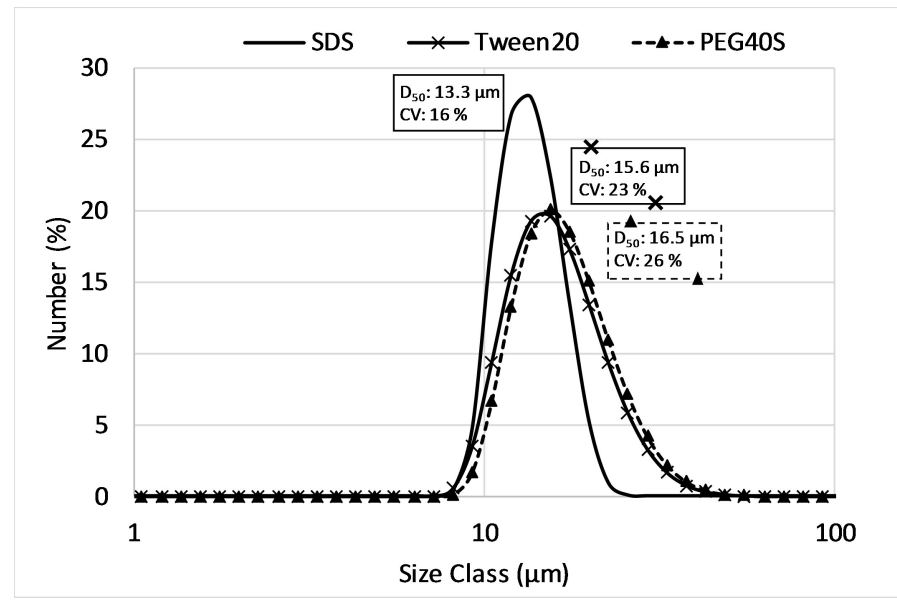

Figure 9: Influence of the surfactants at a concentration of $1.0 \mathrm{wt} \%$ on the microbubble size distribution. Experimental conditions: gaseous phase was $C_{3} F_{8}$, membrane mean pore size $1.1 \mu \mathrm{m}$ and ratio $\Delta \mathrm{P} / P_{B P}: 1.1$

\subsection{Influence of the gaseous phase}

Figure 10 shows the dynamic surface tension of the bubbles as a function of time for the three surfactants at $1.0 \mathrm{wt} \%$. The decrease of the surface tension corresponds to the progressive adsorption of surfactant molecules at the gas-water interface until equilibrium. The initial surface tension value, $\gamma_{0}$, is around 72 $m N . m^{-1}$ at the air-water interface and $70.1 \mathrm{mN} \cdot \mathrm{m}^{-1}$ at the perfluorocarbon-water interface in the absence of surfactant. These values at $\mathrm{t}=0 \mathrm{~s}$ were not measurable in presence of $1.0 \mathrm{wt} \%$ surfactant due to rapid adsorption kinetics. The presence of perfluorocarbon in the microbubbles significantly decreased the interfacial tension at equilibrium, $\gamma_{e q}$, compared with air. A higher decrease of the surface tension at equilibrium was observed from 37.5 to $36.1 \mathrm{mN} . \mathrm{m}^{-1}$ for Tween 20 and 47.3 to $46.3 \mathrm{mN} . \mathrm{m}^{-1}$ for PEG40S after 4 min. For 


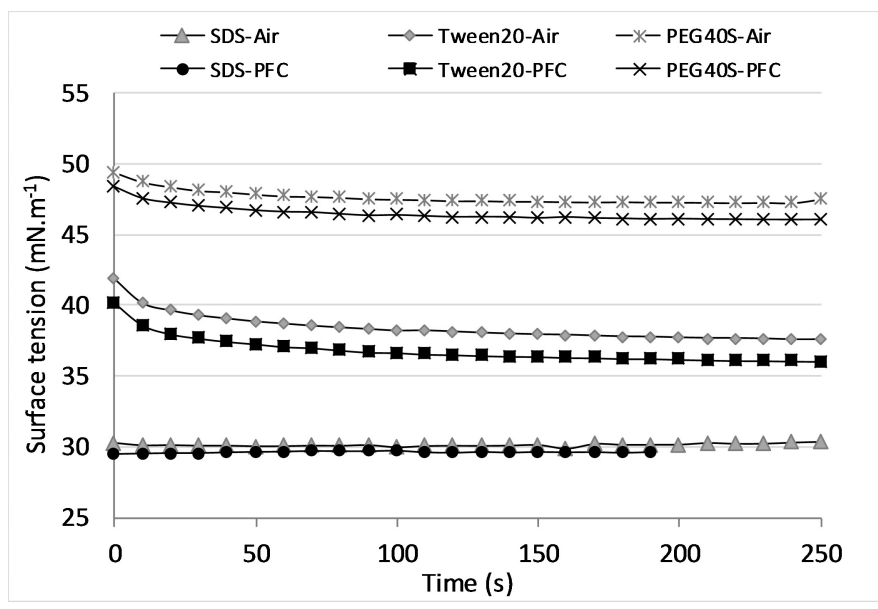

Figure 10: Surface tension at the gaseous/liquid interface for various surfactants at $1.0 \mathrm{wt} \%$ and air or $C_{3} F_{8}$ at room temperature (PFC: Perfluorocarbon)

SDS, this effect was less pronounced due to the fast adsorption of the surfactant at the gas-liquid interface. As reported by Nguyen [15 for phospholipids, the perfluorocarbon gas increased the adsorption kinetic of the surfactant and decreased the equilibrium surface tension. These authors concluded that perfluorocarbon acts as a cosurfactant at the gas-liquid interface, despite the absence of any amphiphilic character.

As explained in the previous sections, a lower surface tension allows obtaining smaller microbubbles, by decreasing the retention force which keeps the microbubble at the pore opening and thus facilitating the microbubble detachment. Indeed, we observed a decrease of the microbubble size with the use of perfluorocarbon gas compared with air for three surfactants (Figure 11). The decrease of microbubble size was less pronounced with SDS than for the two other surfactants, due to a smaller decrease of the equilibrium surface tension.

\subsection{Microbubbles stability}

Stability of perfluorocarbon microbubbles stabilized by the three surfactants at $1.0 \mathrm{wt} \%$ was measured during $90 \mathrm{~s}$. The perfluorocarbon microbubbles were prepared with the membrane of pore size $1.1 \mu \mathrm{m}$ and $\Delta \mathrm{P} / P_{B P}: 1.1$ (Figure 12). Air microbubbles stabilized with SDS and prepared at the same experimental conditions were also tested. In all cases, the mean size of the microbubbles increased with time. This increase was less pronounced for perfluorocarbon microbubbles ( 1.2 for microbubbles stabilized with SDS between $\mathrm{t}=0$ $\mathrm{s}$ and $\mathrm{t}=90 \mathrm{~s}$ ) compared with air microbubbles (2.2 times size increase). For the three surfactants tested, the size of the perfluorocarbon microbubbles increased in a similar way, the increase being equal to 1.29 for Tween 20 and 1.33 for PEG40S. Figures 12 and 13 show two main trends: an increase in microbubble size associated to a decrease in microbubbles concentration. This is the result of the disappearance of the smaller microbubbles while the larger microbubbles grow in size.

The variation of microbubbles diameter over time presents two main stages: (1) an initial growth period, 

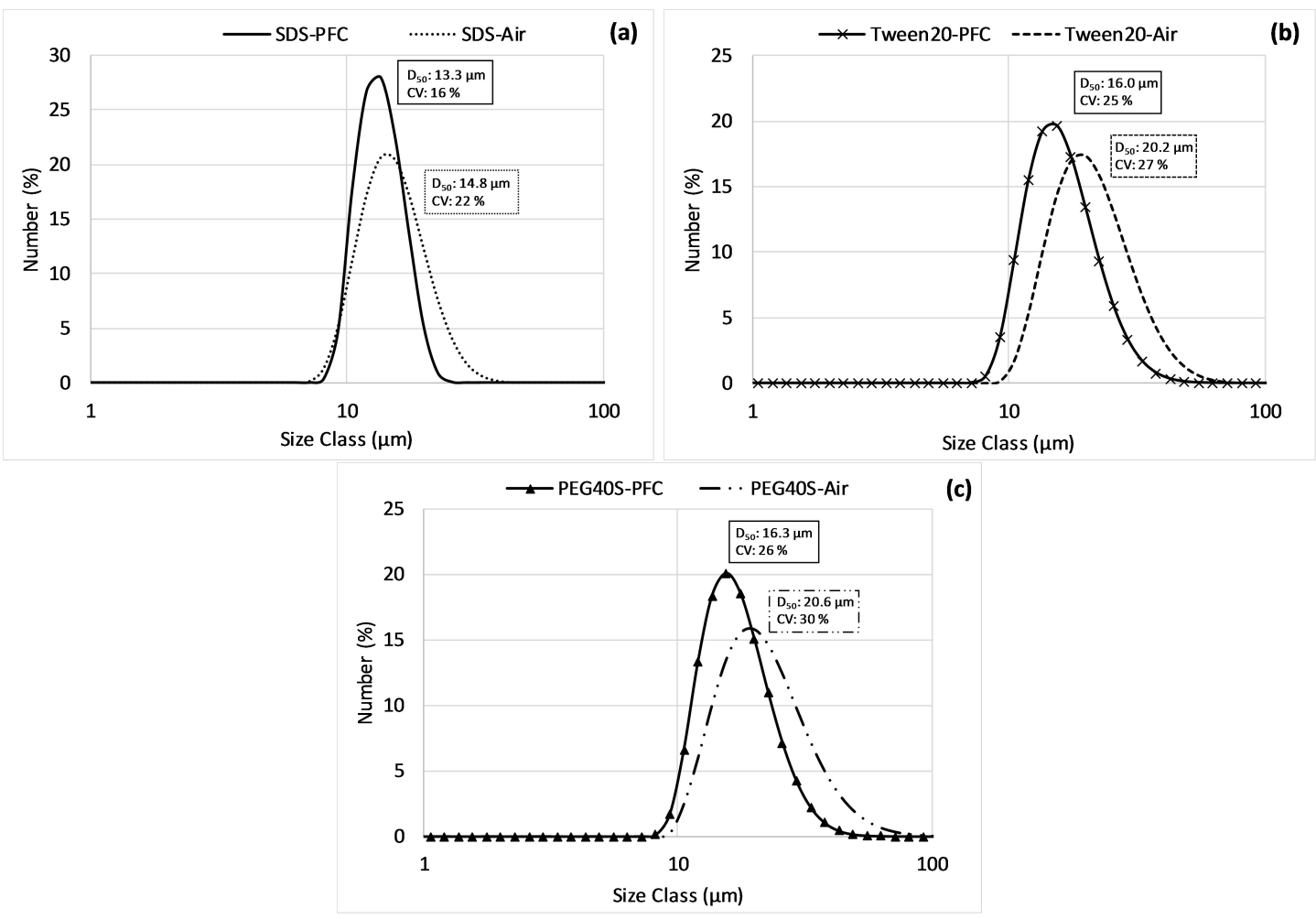

Figure 11: Influence of the gaseous phase on the microbubble size distribution stabilized with 1.0 wt\% (a) SDS, (b) Tween 20 and (c) PEG40S. Experimental conditions: membrane mean pore size $1.1 \mu \mathrm{m}$ and ratio $\Delta \mathrm{P} / P_{B P}$ : 1.1 (PFC: Perfluorocarbon)

(2) followed by microbubble dissolution. The fast initial growth of the microbubble is due to the influx of air dissolved in water diffusing into the PFC microbubble [54. The microbubble dissolution is mainly related to the Laplace pressure experienced by a gas microbubble, given by equation 7 . As gas leaves the microbubble, due to the pressure gradient, the bubble shrinks and the Laplace pressure increases, which accelerates the rate of gas dissolution and the resulting bubble shrinkage. The surfactant at the gas/water interface reduces the gas/water surface tension and thus decreases the Laplace pressure, but does not eliminate it. The rate of bubble shrinkage as a function of time $(t)$ resulting from the dissolution of the gas into the bloodstream is predicted by the equation $8[12,55]$ :

$$
\frac{d r}{d t}=-L D_{w}\left[\frac{P^{*}+\frac{2 \gamma}{r}}{P_{a t m}+\frac{4 \gamma}{3 r}}\right]\left[\frac{1}{r}+\frac{1}{\sqrt{D_{w} t \pi}}\right]
$$

where $\mathrm{L}$ is the Ostwald coefficient, $D_{w}$ is the gas diffusivity in water, $\gamma$ is the surface tension, $P_{a t m}$ is the atmospheric pressure, and $P^{*}$ is the excess pressure [12, 37]. Equation 8 predicts that the inclusion of perfluorocarbon gas with low solubility in water (which gives a low Ostwald coefficient) increases the lifetime of a microbubble. The Ostwald coefficient is defined as the partition coefficient of the gas between the gaseous phase and aqueous phase (ratio of the solubility of the gas in the liquid to the density of the gas). 
The lower the Ostwald coefficient, the longer the lifetime of the microbubbles since perfluorocarbon gases ${ }_{415}\left(L_{C_{3} F_{8}}: 583 \times 10^{+6} ; 25^{\circ} \mathrm{C}\right)$ are less water-soluble than the air $\left(L_{O_{2}}: 31110 \times 10^{+6}\right.$ and $L_{N_{2}}: 15880 \times 10^{+6}$; $25^{\circ} \mathrm{C}$ ) [40]. The gas diffusion coefficient, $D_{w}$, is inversely proportional to the gas molecules size, which results in a decrease in diffusivity for $C_{3} F_{8}\left(188 \mathrm{~g} \mathrm{~mol}^{-1}\right)$ compared to air $\left(28.9 \mathrm{~g}^{\mathrm{mol}} \mathrm{mol}^{-1}\right)$.

The concentration of perfluorocarbon microbubbles stabilized with SDS was constant during $60 \mathrm{~s}$, before decreasing, while the air microbubbles concentration decreased from $t=0 \mathrm{~s}$ (Figure 13). The mechanism by which larger microbubbles grow in size at the expense of smaller bubbles is called Ostwald ripening. The dissolution of the gas in the aqueous phase increases as the interfacial curvature increases and then the bubble size decreases quickly. Thus, perfluorocarbon microbubbles showed a better stability than air microbubbles.

Another phenomenon occurs at the gas-liquid interface, where the dynamic adsorption and desorption of the surfactant molecules creates short spaces between molecules, facilitating the gas transfer [56. In the case of perfluorocarbon microbubbles stabilized with PEG40S, the gas transfer into the aqueous phase could be increased, due to the low cohesive shell created by steric repulsion between the hydrophilic heads of the PEG40S macromolecules. This could explain the faster decrease of PEG40S perfluorocarbon microbubble concentration.

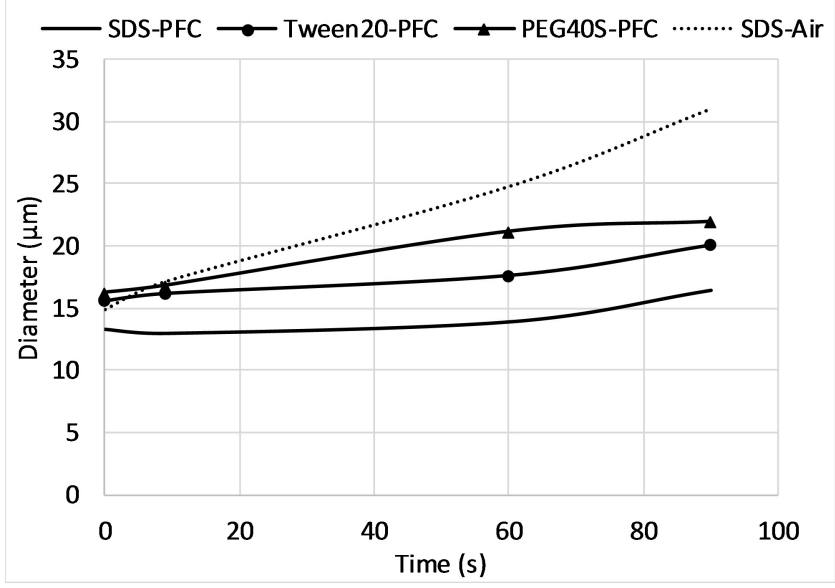

Figure 12: Variation of microbubble diameter, $D_{50}$, as a function of time for various surfactants with $C_{3} F_{8}$ or air. Experimental conditions: membrane mean pore size $1.1 \mu \mathrm{m}$ and ratio $\Delta \mathrm{P} / P_{B P}: 1.1$ (PFC: Perfluorocarbon)

However, the lifetime of the microbubbles obtained with the surfactants was low compared with microbubbles stabilized by lipids [14. These microbubbles could then be used as transiently stable microbubbles as shown by Dhanaliwala et al. [27, as large microbubbles $(19 \mu \mathrm{m})$ produced by microfluidic process were administered in vivo in a mouse and shown to generate a large acoustic response in both the right and left ventricles. 


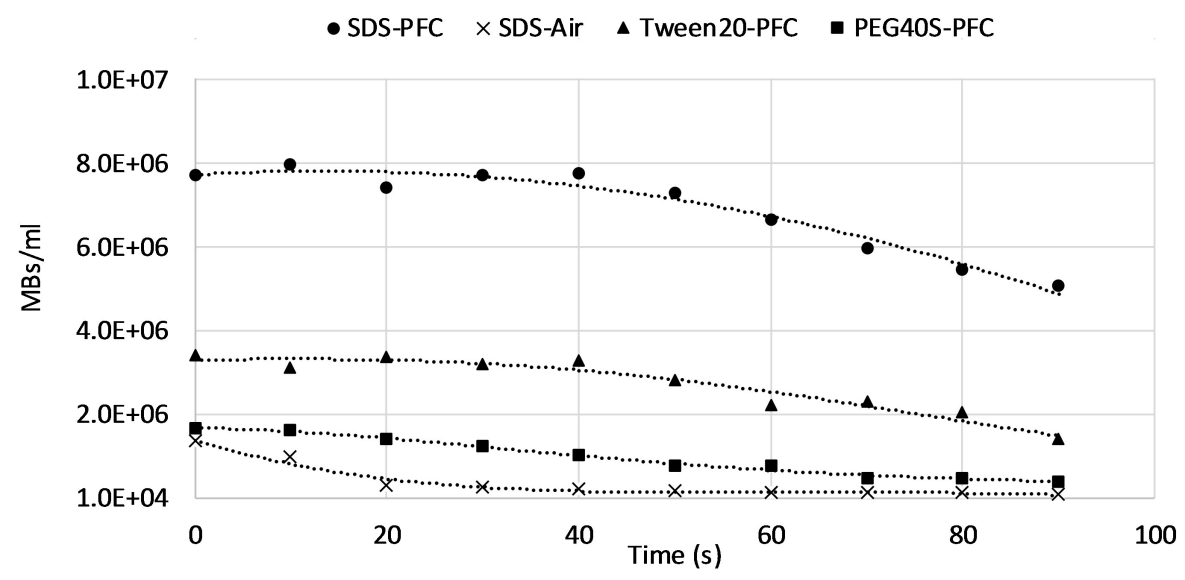

Figure 13: Variation of concentration $\mathrm{MBs} / \mathrm{ml}$ as a function of time for various surfactants with $C_{3} F_{8}$ or air. Experimental conditions: membrane mean pore size $1.1 \mu \mathrm{m}$ and ratio $\Delta \mathrm{P} / P_{B P}: 1.1$ (PFC: Perfluorocarbon)

\section{Conclusion}

In this study, we produced successfully perfluorocarbon microbubbles with the use of tubular SPG membranes with a $1.1 \mu \mathrm{m}$ pore size and $\Delta \mathrm{P} / P_{B P}: 1.1$. The microbubbles were generated with a mean diameter of 13.3, 15.6 and $16.5 \mu \mathrm{m}$ with a narrow size distribution for the three surfactants SDS, Tween20 and PEG40S, respectively. The effect of transmembrane pressure, shear stress at the membrane surface due to the water phase flow, and pore size on the microbubbles size was investigated. The transmembrane pressure, until a threshold of $\Delta \mathrm{P} / P_{B P}<1.5$, and shear stress did not affect the size of the microbubbles which were produced at a high yield $\left(\sim 10^{+10} \mathrm{MBs} / \mathrm{min}\right)$. As expected, the decrease of the pore size led to a decrease of the microbubble size, but the dilution of microbubbles into a beaker before the size measurement by laser diffraction increased their dissolution which impacted their size and size distribution. This study also showed that the perfluorocarbon gas decreased the surface tension at the gas-water interface to produce smaller microbubbles compared with air microbubbles and that the hydrophobicity properties of the perfluorocarbon gas increased the microbubbles stability. The main phenomenon governing the formation of monodispersed microbubbles by the membrane technique is the adsorption kinetics of the surfactant at the new gas-liquid interface at the pore opening. 


\section{Nomenclature}

\begin{tabular}{|c|c|c|}
\hline & A & Effective membrane area $\left(m^{2}\right)$ \\
\hline & $D_{i}$ & Mean diameter in the class i $(\mu \mathrm{m})$ \\
\hline & $D_{n}$ & Microbubble diameter at $\mathrm{n} \%$ of the cumulative number $(\mu \mathrm{m})$ \\
\hline & $D_{p}$ & Pore diameter $(\mu \mathrm{m})$ \\
\hline & $D_{w}$ & Gas diffusivity in water $\left(m^{2} . s-1\right)$ \\
\hline & $\mathrm{J}$ & Phase flux of the gaseous phase $\left(m^{3} \cdot m^{-2} \cdot s-1\right)$ \\
\hline & $\mathrm{L}$ & Ostwald's coefficient \\
\hline & $n_{i}$ & Number of microbubbles in the class i \\
\hline & $P_{\text {atm }}$ & Atmospheric pressure $(\mathrm{Pa})$ \\
\hline 450 & $P^{*}$ & Excess pressure $(\mathrm{Pa})$ \\
\hline & $P_{P B}$ & Bubble point pressure (Bar) \\
\hline & $\Delta \mathrm{P}$ & Transmembrane pressure (Bar) \\
\hline & $\delta \mathrm{P}$ & Laplace pressure $(\mathrm{Pa})$ \\
\hline & $\mathrm{Q}$ & Volumic flowrate of the gaseous phase $\left(m^{3} \cdot s-1\right)$ \\
\hline & $\mathrm{r}$ & Radius of the microbubble \\
\hline & $\mathrm{R}$ and $R_{2}$ & Inner radius of the membrane tube $(\mathrm{m})$ \\
\hline & $R_{1}$ & Rod radius $(\mathrm{m})$ \\
\hline & $\mathrm{t}$ & Time (s) \\
\hline & $V_{d}$ & Mean velocity of the continuous phase in the tube $\left(m . s^{-1}\right)$ \\
\hline
\end{tabular}

\section{Greek Symbols}

$\gamma_{0} \quad$ Surface tension at $\mathrm{t}=0 \mathrm{~s}\left(\mathrm{mN} . \mathrm{m}^{-1}\right)$

$\gamma_{e q} \quad$ Surface tension at the equilibrium $\left(m N . m^{-1}\right)$

$\mu \quad$ Dynamic viscosity (Pa.s)

$\tau_{w} \quad$ Shear stress at the membrane surface $(\mathrm{Pa})$

$\Theta \quad$ Contact angle 


\section{Abreviations}

$C_{3} F_{8} \quad$ Octafluoropropane

CEHDA Coaxial electrohydrodynamic atomisation

CMC Critical micelle concentration

CV Coefficient variation

PEG40S Polyoxyethylene (40) stearate

PTFE Polytetrafluorethylene

Tween20 Polyoxyethylene (20) sorbitan monolaurate

SDS Sodium dodecyl sulfate

SPG Shirasu Porous Glass

q [5] K. Ferrara, R. Pollard, M. Borden, Ultrasound Microbubble Contrast Agents: Fundamentals and Application to Gene and Drug Delivery, Annual Review of Biomedical Engineering 9 (1) (2007) 415-447. doi:10.1146/annurev.bioeng.8.061505.095852

URL http://www . annualreviews.org/doi/abs/10.1146/annurev.bioeng.8.061505.095852

475

口 [1] M. Kukizaki, T. Wada, Effect of the membrane wettability on the size and size distribution of microbubbles formed from Shirasu-porous-glass (SPG) membranes, Colloids and Surfaces A: Physicochemical and Engineering Aspects 317 (1-3) (2008) 146-154. doi:10.1016/j.colsurfa.2007.10.005.

URL http://linkinghub.elsevier.com/retrieve/pii/S0927775707009168

q [3] C. Liu, T.-M. Xiao, J. Zhang, L. Zhang, J.-L. Yang, M. Zhang, Effect of membrane wettability on 465 membrane fouling and chemical durability of SPG membranes used in a microbubble-aerated biofilm

1 reactor, Separation and Purification Technology 127 (2014) 157-164. doi:10.1016/j.seppur.2014. 03.001 .

URL http://linkinghub.elsevier.com/retrieve/pii/S1383586614001439

[4] W. Krause (Ed.), Optical, ultrasound, x-ray and radiopharmaceutical imaging, no. 2.2002 in Contrast agents, Springer, Berlin, 2002, oCLC: 314296713.

6] S. Tinkov, R. Bekeredjian, G. Winter, C. Coester, Microbubbles as ultrasound triggered drug carriers, Journal of Pharmaceutical Sciences 98 (6) (2009) 1935-1961. doi:10.1002/jps.21571.

URL http://linkinghub.elsevier.com/retrieve/pii/S0022354916329835 
[7] J. A. Feshitan, C. C. Chen, J. J. Kwan, M. A. Borden, Microbubble size isolation by differential centrifugation, Journal of Colloid and Interface Science 329 (2) (2009) 316-324. doi:10.1016/j.jcis.2008. 09.066 .

URL http://linkinghub.elsevier.com/retrieve/pii/S0021979708012149

[ [8] M. A. Parrales, J. M. Fernandez, M. Perez-Saborid, J. A. Kopechek, T. M. Porter, Acoustic charac-

1. terization of monodisperse lipid-coated microbubbles: Relationship between size and shell viscoelas-

n tic properties, The Journal of the Acoustical Society of America 136 (3) (2014) 1077-1084. doi: $10.1121 / 1.4890643$

URL http://asa.scitation.org/doi/10.1121/1.4890643

[9] Michel Schneider, BR1 : A new ultrasonographic contrast agent based on sulfur hesafluoride-filled microbubbles, Investigate radiology.

[10] S. Rossi, C. Szjjrt, F. Gerber, G. Waton, M. P. Krafft, Fluorous materials in microbubble engineering science and technologyDesign and development of new bubble preparation and sizing technologies, Journal of Fluorine Chemistry 132 (12) (2011) 1102-1109. doi:10.1016/j.jfluchem.2011.06.032.

URL http://linkinghub.elsevier.com/retrieve/pii/S002211391100220X

[11] M. P. Krafft, Fluorine in medical microbubbles Methodologies implemented for engineering and ina vestigating fluorocarbon-based microbubbles, Journal of Fluorine Chemistry 177 (2015) 19-28. doi: $10.1016 / j \cdot j f l u c h e m .2015 .02 .013$

URL http://linkinghub.elsevier.com/retrieve/pii/S0022113915000585

[12] A. Kabalnov, D. Klein, T. Pelura, E. Schutt, J. Weers, Dissolution of multicomponent microbubbles in the bloodstream: 1. Theory, Ultrasound in medicine \& biology 24 (5) (1998) 739-749.

URL http://www.sciencedirect.com/science/article/pii/S0301562998000349

[13] S. Rossi, G. Waton, M. P. Krafft, Small Phospholipid-Coated Gas Bubbles Can Last Longer than Larger Ones, ChemPhysChem 9 (14) (2008) 1982-1985. doi:10.1002/cphc.200800386.

URL http://doi .wiley .com/10.1002/cphc.200800386

[14] C. Szjjrt, S. Rossi, G. Waton, M. P. Krafft, Effects of Perfluorocarbon Gases on the Size and Stability

n Characteristics of Phospholipid-Coated Microbubbles: Osmotic Effect versus Interfacial Film Stabiliza-

tion, Langmuir 28 (2) (2012) 1182-1189. doi:10.1021/la2043944.

URL http://pubs .acs .org/doi/abs/10.1021/la2043944

[15] P. N. Nguyen, T. T. Trinh Dang, G. Waton, T. Vandamme, M. P. Krafft, A Nonpolar, Nonamphiphilic Molecule Can Accelerate Adsorption of Phospholipids and Lower Their Surface Tension at the Air/Water Interface, ChemPhysChem 12 (14) (2011) 2646-2652. doi:10.1002/cphc.201100425.

URL http://doi .wiley . com/10.1002/cphc.201100425 
[16] S. R. Sirsi, M. A. Borden, Microbubble compositions, properties and biomedical applications, Bubble Science, Engineering \& Technology 1 (1-2) (2009) 3-17. doi:10.1179/175889709X446507

URL http://www .maneyonline.com/doi/abs/10.1179/175889709X446507

[17] V. Sanna, G. Pintus, P. Bandiera, R. Anedda, S. Punzoni, B. Sanna, V. Migaleddu, S. Uzzau, M. Sechi, Development of Polymeric Microbubbles Targeted to Prostate-Specific Membrane Antigen as Prototype of Novel Ultrasound Contrast Agents, Molecular Pharmaceutics 8 (3) (2011) 748-757. doi:10.1021/ mp100360g.

URL http://pubs .acs.org/doi/abs/10.1021/mp100360g

[18] R. Shih, A. P. Lee, Post-Formation Shrinkage and Stabilization of Microfluidic Bubbles in Lipid Solution, Langmuir 32 (8) (2016) 1939-1946. doi:10.1021/acs.langmuir.5b03948

URL http://pubs .acs .org/doi/10.1021/acs . langmuir.5b03948

[19] Z. Xing, H. Ke, J. Wang, B. Zhao, X. Yue, Z. Dai, J. Liu, Novel ultrasound contrast agent based on microbubbles generated from surfactant mixtures of Span 60 and polyoxyethylene 40 stearate, Acta Biomaterialia 6 (9) (2010) 3542-3549. doi:10.1016/j.actbio.2010.03.007. URL http://linkinghub.elsevier.com/retrieve/pii/S1742706110001339

[20] Y. Ando, H. Tabata, M. Sanchez, A. Cagna, D. Koyama, M. P. Krafft, Microbubbles with a SelfAssembled Poloxamer Shell and a Fluorocarbon Inner Gas, Langmuir 32 (47) (2016) 12461-12467. doi:10.1021/acs. langmuir.6b01883.

URL http://pubs .acs .org/doi/abs/10.1021/acs. langmuir.6b01883 investigating fluorocarbon-based microbubbles, Journal of Fluorine Chemistry 177 (2015) 19-28. doi: 
10.1016/j.jfluchem.2015.02.013.

URL http://linkinghub.elsevier.com/retrieve/pii/S0022113915000585

[33] M. Kukizaki, Microbubble formation using asymmetric Shirasu porous glass (SPG) membranes and porous ceramic membranes - A comparative study, Colloids and Surfaces A: Physicochemical and Engineering Aspects 340 (1-3) (2009) 20-32. doi:10.1016/j.colsurfa.2009.02.033

URL http://linkinghub.elsevier.com/retrieve/pii/S0927775709001095 
[34] M. Kukizaki, M. Goto, Size control of nanobubbles generated from Shirasu-porous-glass (SPG) membranes, Journal of Membrane Science 281 (1-2) (2006) 386-396. doi:10.1016/j.memsci.2006.04.007. URL http://linkinghub.elsevier.com/retrieve/pii/S0376738806002432

[35] M. Kukizaki, Y. Baba, Effect of surfactant type on microbubble formation behavior using Shirasu porous glass (SPG) membranes, Colloids and Surfaces A: Physicochemical and Engineering Aspects 326 (3) (2008) 129-137. doi:10.1016/j.colsurfa.2008.05.025.

URL http://www.sciencedirect.com/science/article/pii/S0927775708003452

[36] S. M. Joscelyne, G. Trägardh, Membrane emulsificationa literature review, Journal of Membrane Science 169 (1) (2000) 107-117.

URL http://www.sciencedirect.com/science/article/pii/S0376738899003348

[37] E. G. Schutt, D. H. Klein, R. M. Mattrey, J. G. Riess, Injectable Microbubbles as Contrast Agents for Diagnostic Ultrasound Imaging: The Key Role of Perfluorochemicals, Angewandte Chemie International Edition 42 (28) (2003) 3218-3235. doi:10.1002/anie.200200550. URL http://onlinelibrary.wiley.com.docelec.univ-lyon1.fr/doi/10.1002/anie.200200550/ abstract

[38] Q. Xu, M. Nakajima, S. Ichikawa, N. Nakamura, P. Roy, H. Okadome, T. Shiina, Effects of surfactant and electrolyte concentrations on bubble formation and stabilization, Journal of Colloid and Interface Science 332 (1) (2009) 208-214. doi:10.1016/j.jcis.2008.12.044. URL http://linkinghub.elsevier.com/retrieve/pii/S0021979708016810

[39] M. S. Kalekar, S. S. Bhagwat, Dynamic Behavior of Surfactants in Solution, Journal of Dispersion Science and Technology 27 (7) (2006) 1027-1034. doi:10.1080/01932690600767080.

URL http://www .tandfonline.com/doi/abs/10.1080/01932690600767080

[40] T. Nakashima, M. Kawano, M. Shimizu, Articles of porous glass and process for preparing the same, US Patent No. 4,657,875, 1987.

[41] G. T. Vladisavljević, Integrated membrane processes for the preparation of emulsions, particles and bubbles, in: Integrated Membrane Systems and Process, Wiley (2015) 79-140 doi:10.1002/ $9781118739167 . \operatorname{ch} 5$

[42] C. Charcosset, Membranes for the preparation of emulsions and particles, in: Membrane Processes in Biotechnology and Pharmaceutics, Elsevier, 2012, pp. 213-251. doi:10.1016/B978-0-444-56334-7. 00006-X.

URL http://linkinghub.elsevier.com/retrieve/pii/B978044456334700006X 
[43] H. S. Goran T. Vladisavljević, Preparation and analysis of oil-in-water emulsions with a narrow droplet a size distribution using Shirasu-porous-glass (SPG) membranes, Desalination 144 (2002) 167-172. doi: 10.1016/S0011-9164(02)00307-7.

[44] J. Benjamins, A. Cagna, E. H. Lucassen-Reynders, Viscoelastic properties of triacylglycerol/water interfaces covered by proteins, Colloids and Surfaces A: Physicochemical and Engineering Aspects 114 (1996) 245-254. doi:10.1016/0927-7757(96)03533-9.

[45] Talleyrand, Fluides en écoulement méthodes et modèles - chapitre 6 Ecoulement Interne, 1991.

[46] B. E. Oeffinger, M. A. Wheatley, Development and characterization of a nano-scale contrast agent, Ultrasonics 42 (1-9) (2004) 343-347. doi:10.1016/j.ultras.2003.11.011. URL http://linkinghub.elsevier.com/retrieve/pii/S0041624X03002117

[47] R. Liu, G. Ma, F.-T. Meng, Z.-G. Su, Preparation of uniform-sized PLA microcapsules by combining Shirasu Porous Glass membrane emulsification technique and multiple emulsion-solvent evaporation method, Journal of Controlled Release 103 (1) (2005) 31-43. doi:10.1016/j.jconrel.2004.11.025. URL http://linkinghub.elsevier.com/retrieve/pii/S0168365904005863

[52] m. Lepercq-Bost, M.-L. Giorgi, A. Isambert, C. Arnaud, Use of the capillary number for the prediction of droplet size in membrane emulsification, Journal of Membrane Science 314 (1-2) (2008) 76-89. doi:

[48] M. Yasuno, S. Sugiura, S. Iwamoto, M. Nakajima, A. Shono, K. Satoh, Monodispersed microbubble formation using microchannel technique, AIChE Journal 50 (12) (2004) 3227-3233. doi:10.1002/aic. 10276.

URL http://doi.wiley.com/10.1002/aic.10276

[49] G. Vladisavljević, M. Shimizu, T. Nakashima, Permeability of hydrophilic and hydrophobic Shirasuporous-glass (SPG) membranes to pure liquids and its microstructure, Journal of Membrane Science 250 (1-2) (2005) 69-77. doi:10.1016/j.memsci.2004.10.017.

URL http://linkinghub.elsevier.com/retrieve/pii/S0376738804007112

[50] V. Schröder, O. Behrend, H. Schubert, Effect of dynamic interfacial tension on the emulsification process using microporous, ceramic membranes, Journal of Colloid and Interface Science 202 (2) (1998) 334-340. doi:10.1006/jcis.1998.5429.

[51] M. Kukizaki, Shirasu porous glass (SPG) membrane emulsification in the absence of shear flow at

a the membrane surface: Influence of surfactant type and concentration, viscosities of dispersed and continuous phases, and transmembrane pressure, Journal of Membrane Science 327 (1-2) (2009) 234243. doi:10.1016/j.memsci.2008.11.026.

URL http://linkinghub.elsevier.com/retrieve/pii/S0376738808009903 
10.1016/j.memsci.2008.01.023.

URL http://linkinghub.elsevier.com/retrieve/pii/S0376738808000719

640

650

[53] M. Yasuno, M. Nakajima, S. Iwamoto, T. Maruyama, S. Sugiura, I. Kobayashi, A. Shono, K. Satoh, Visualization and characterization of SPG membrane emulsification, Journal of membrane science 210 (1) (2002) 29-37.

URL http://www.sciencedirect.com/science/article/pii/S037673880200371X

[54] J. J. Kwan, M. A. Borden, Microbubble Dissolution in a Multigas Environment, Langmuir 26 (9) (2010) 6542-6548. doi:10.1021/la904088p.

URL http://pubs .acs .org/doi/abs/10.1021/la904088p

[55] P. S. Epstein, M. S. Plesset, On the Stability of Gas Bubbles in LiquidGas Solutions, The Journal of Chemical Physics 18 (11) (1950) 1505-1509. doi:10.1063/1.1747520.

URL http://aip.scitation.org/doi/10.1063/1.1747520

[56] J. Hanwright, J. Zhou, G. M. Evans, K. P. Galvin, Influence of Surfactant on Gas Bubble Stability,

Langmuir 21 (11) (2005) 4912-4920. doi:10.1021/la0502894.

URL http://pubs .acs .org/doi/abs/10.1021/la0502894 